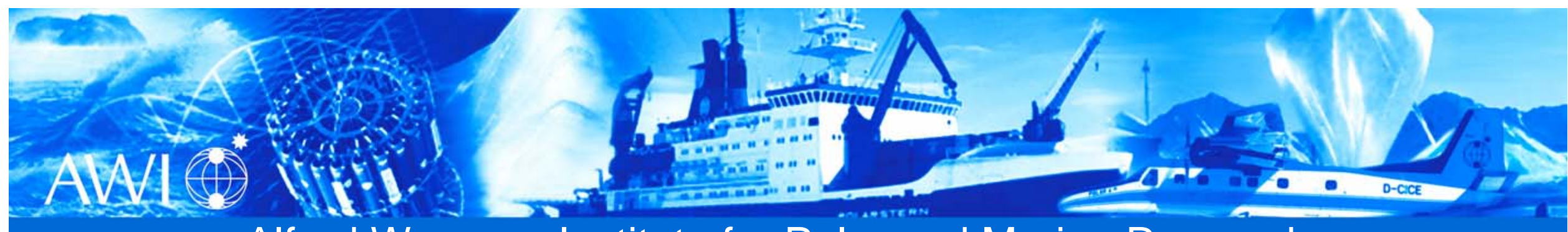

Alfred Wegener Institute for Polar and Marine Research

\title{
Thermal tolerance in the lugworm Arenicola marina: measures of climate dependent organismal performance
}

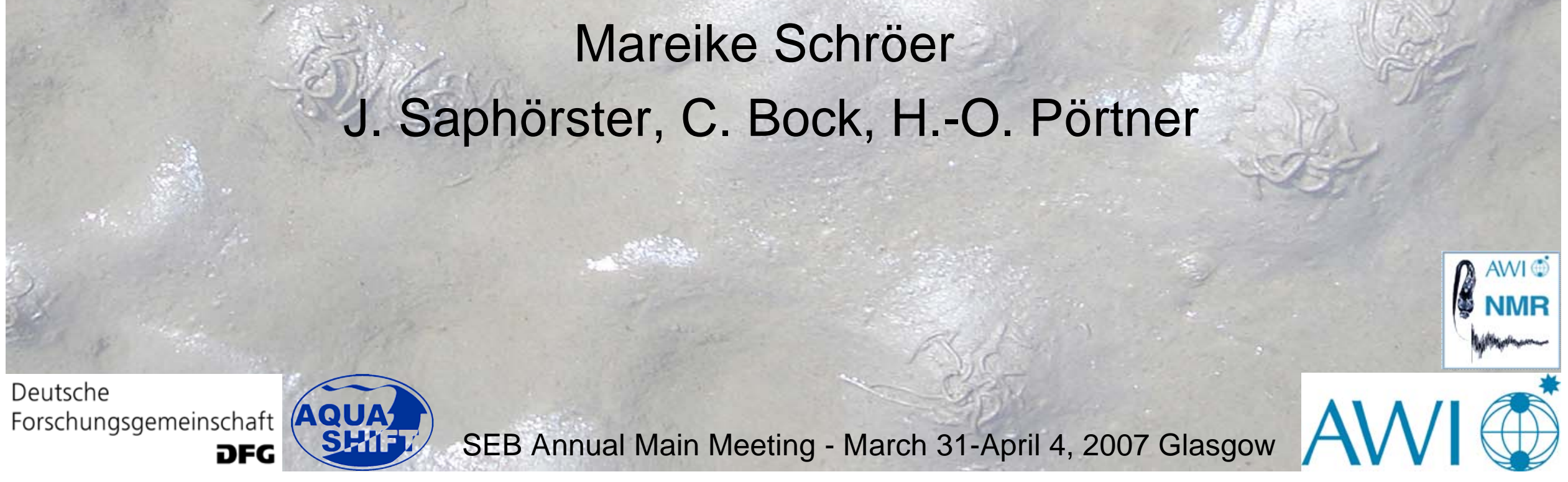




\section{Model organism}

The lugworm Arenicola marina beside it's burrow

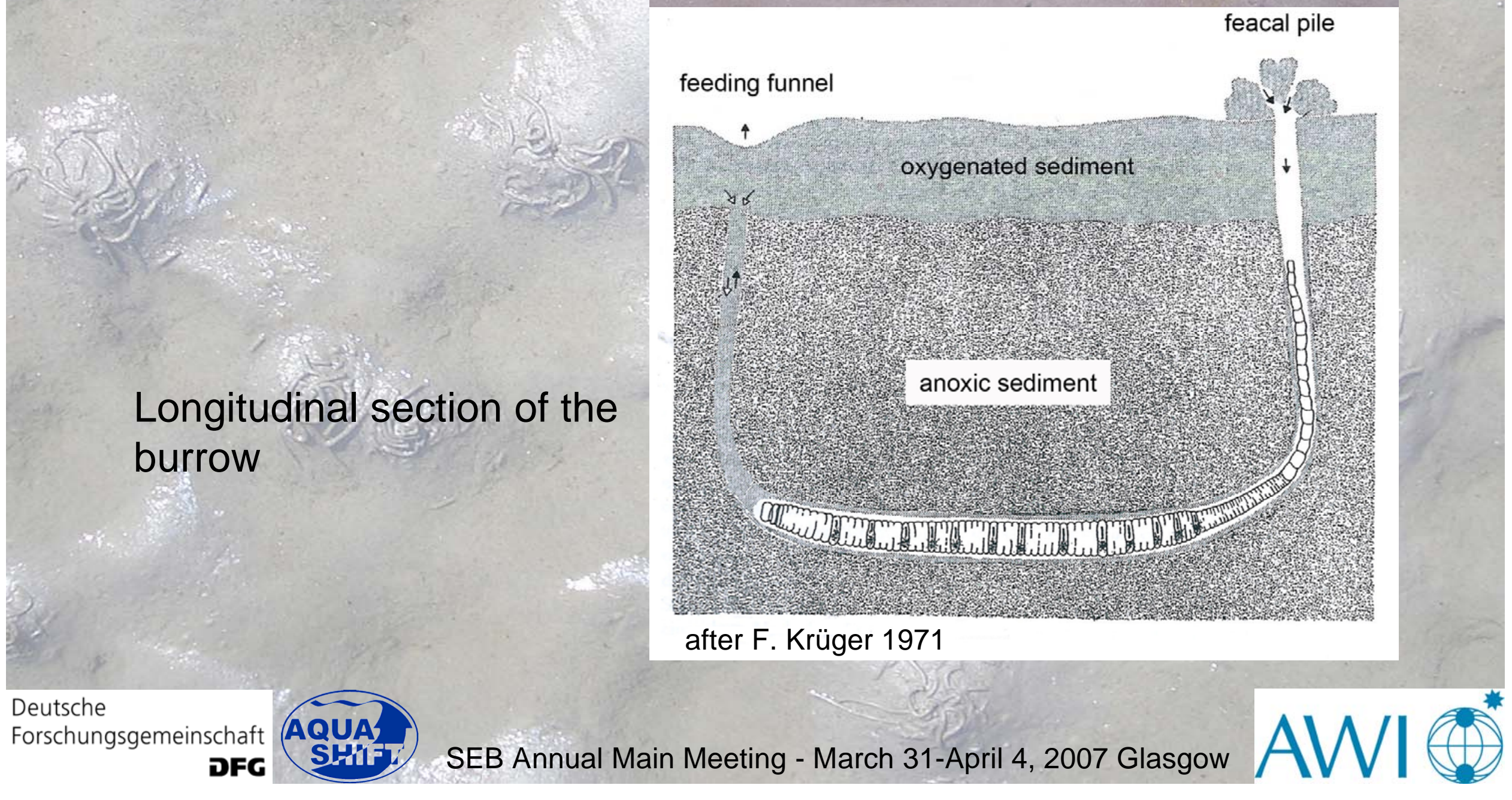




\section{Organismal performance}

As seen in fishes (Pörtner and Knust 2007), long-term warming

$\Rightarrow>$ reduced performance (growth, reproduction, muscle exercise,...)

=> ecological consequences:

- decreased abundance

- local extinction

- shift in distribution

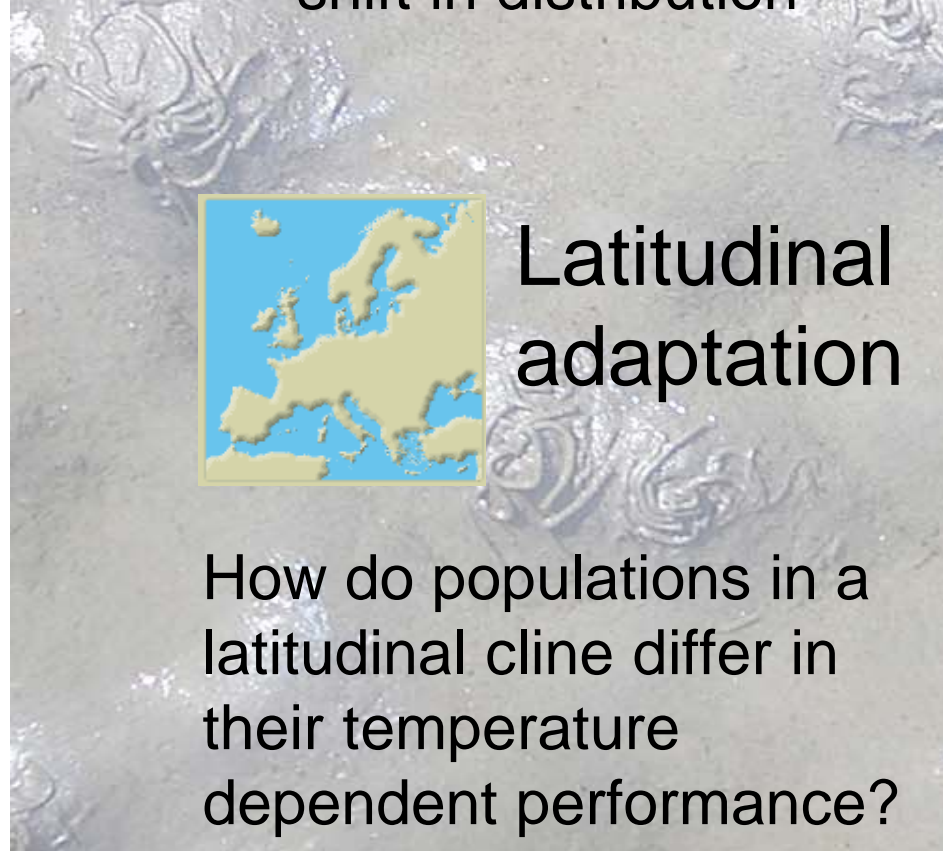




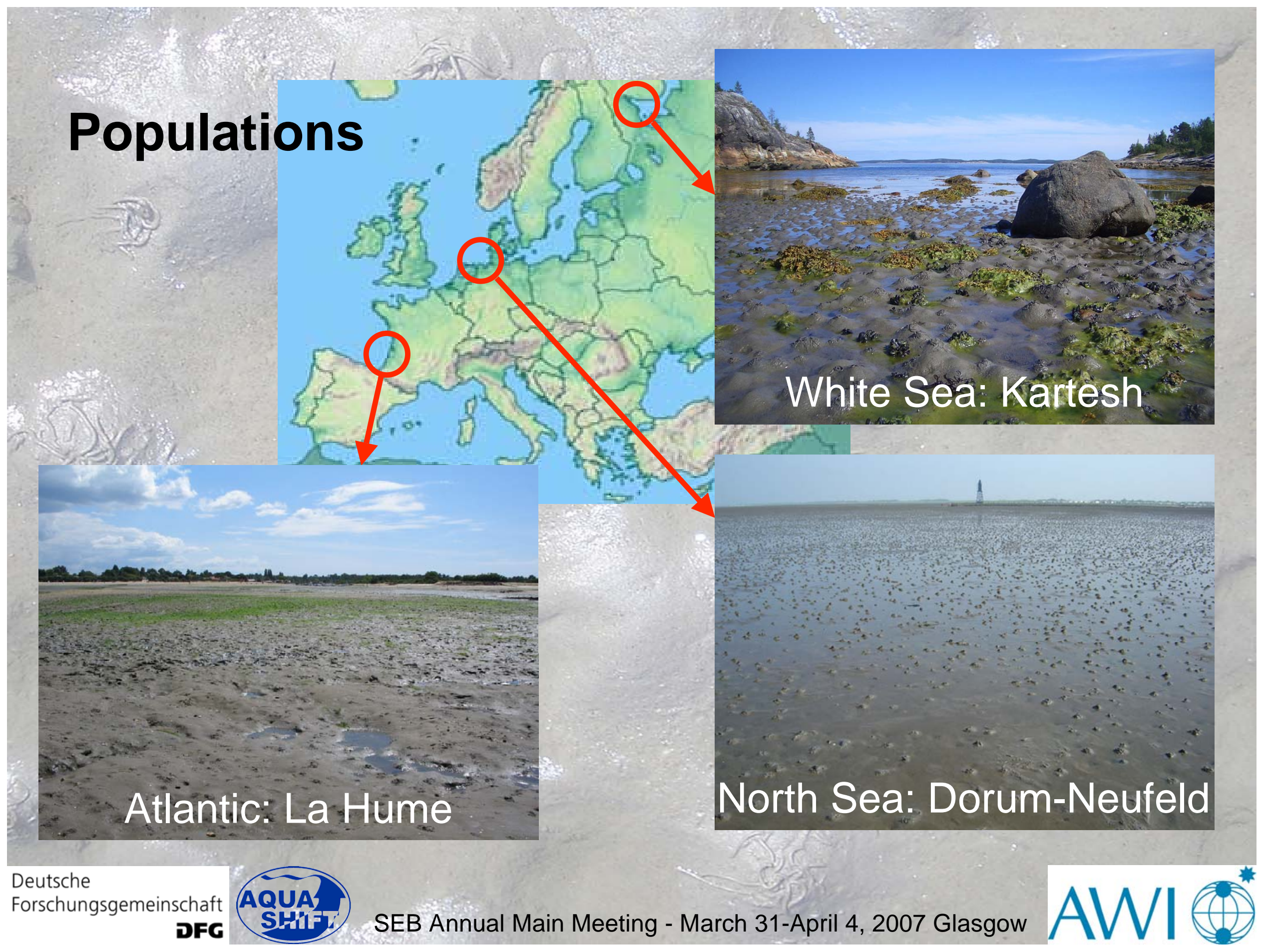




\section{Organismal performance}

As seen in fishes (Pörtner and Knust 2007), long-term warming beyond pejus temperatures

$\Rightarrow$ reduced performance (growth, reproduction, muscle exercise,...)

=> ecological consequences:

- decreased abundance

- local extinction

- shift in distribution

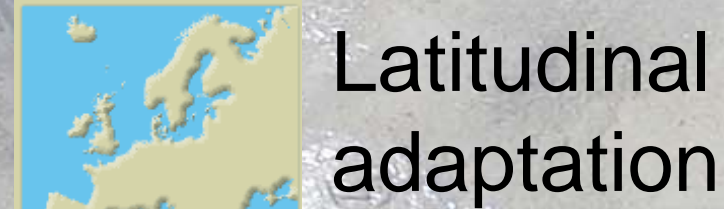

How do populations in a latitudinal cline differ in their temperature dependent performance?

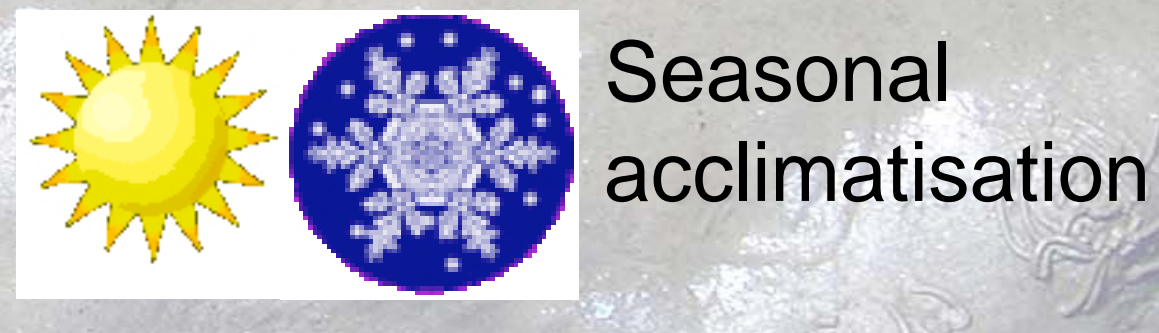

In which way does performance change with seasonal acclimatisation? 


\section{Seasonal comparisons in the same population}

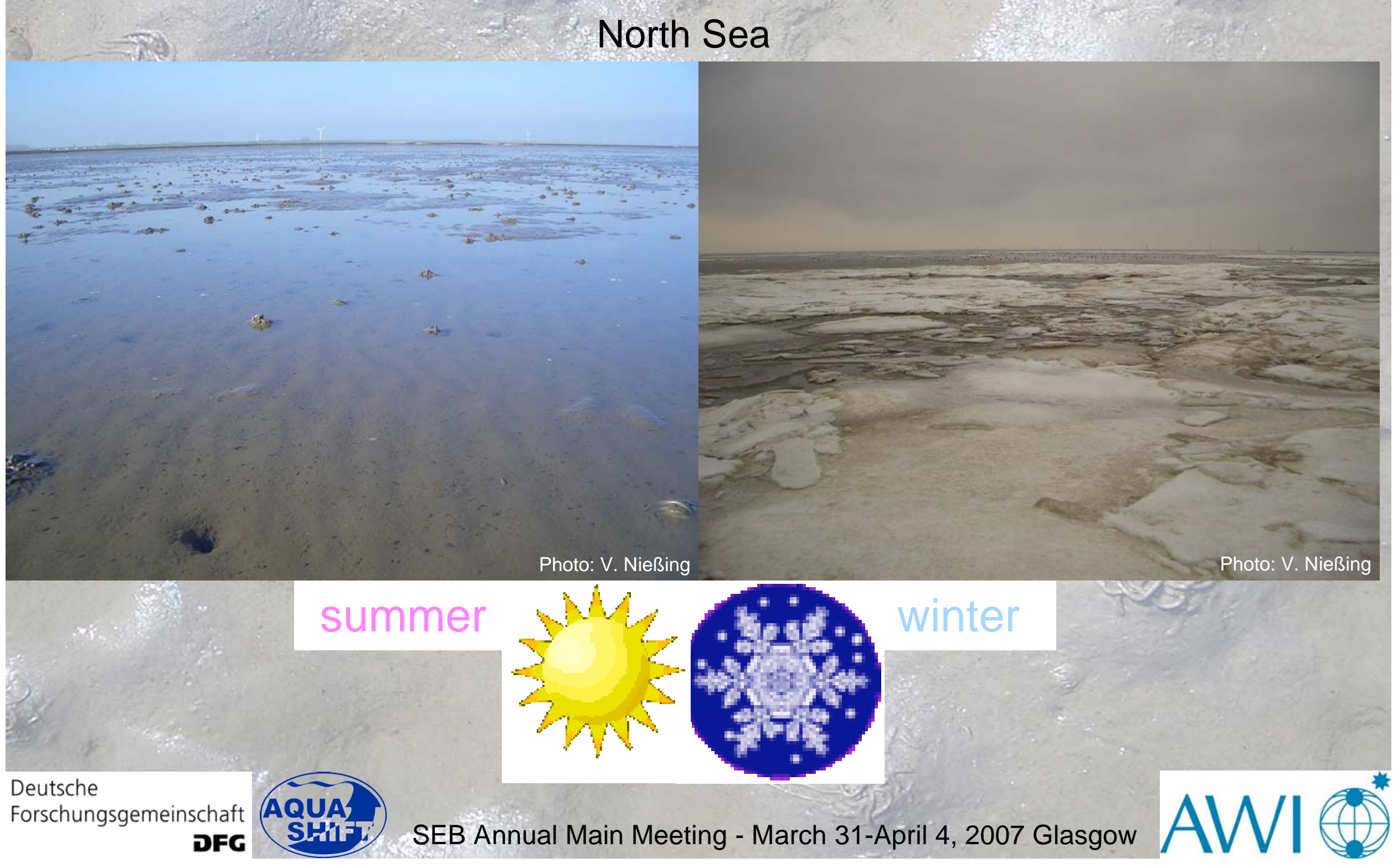




\section{Temperature thresholds and performance}
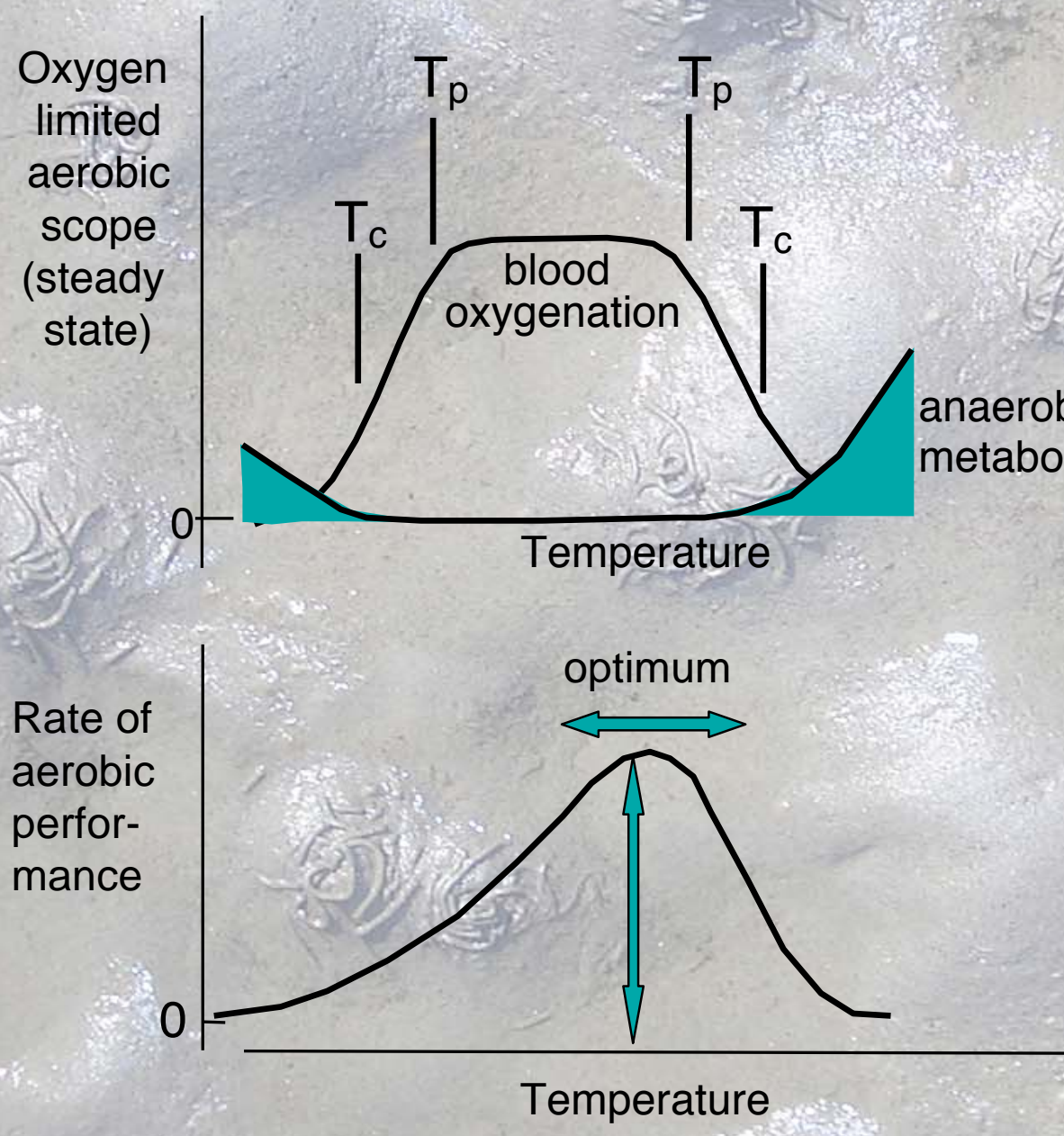

After: Pörtner et al. 2004
$\mathbf{T}_{\mathbf{p}}$ : pejus temperatures oxygen supply limit decreasing blood oxygenation loss of performance anaerobic metabolism $\mathbf{T}_{\mathbf{c}}$ : critical temperatures metabolism turns anaerobic survival time limited unless acclimatisation occurs

Performance curve: oxygen supply budget above basic metabolism 


\section{Balance of oxygen demand and supply}

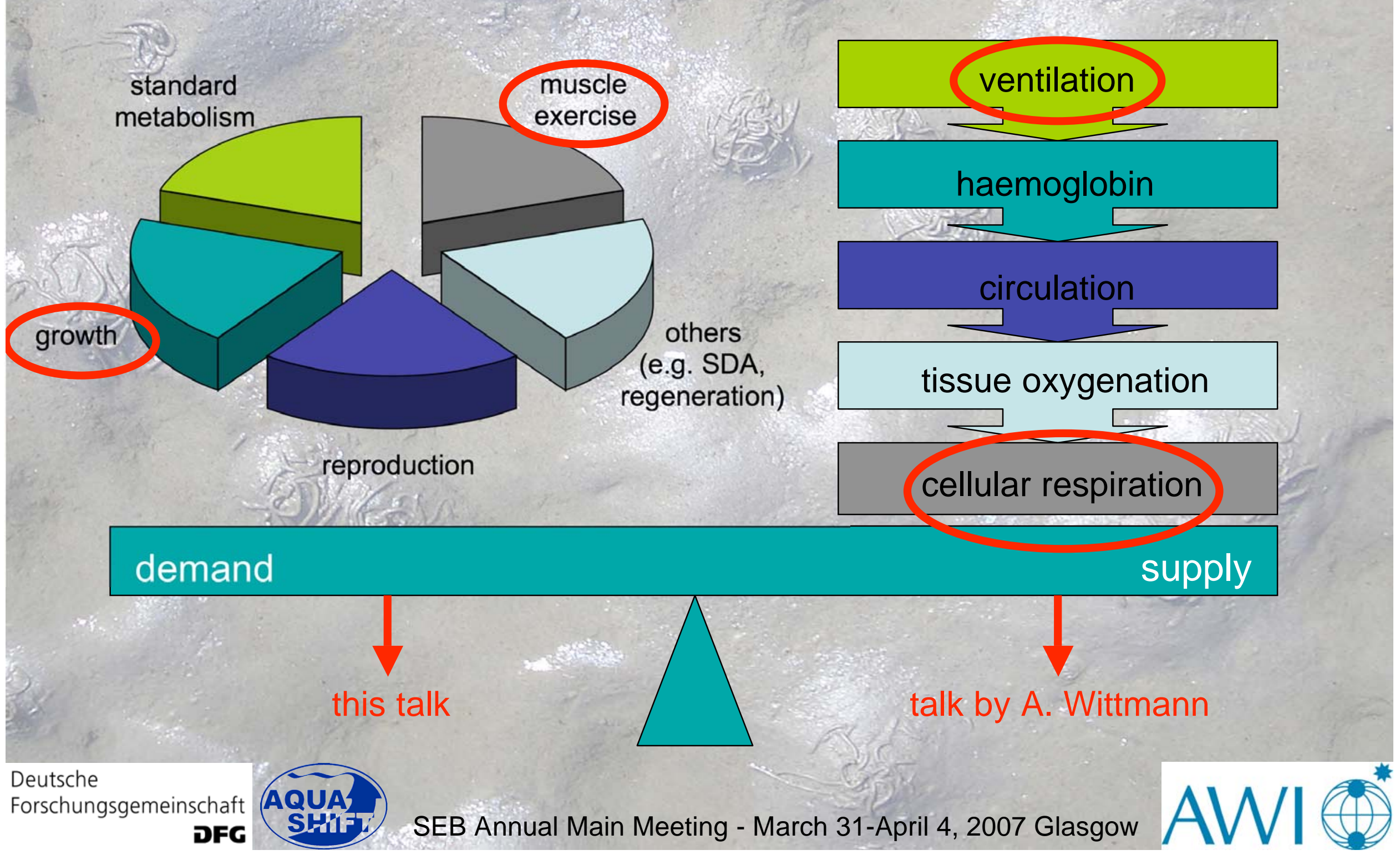




\section{Muscle exercise: digging activity}

\section{Method:}

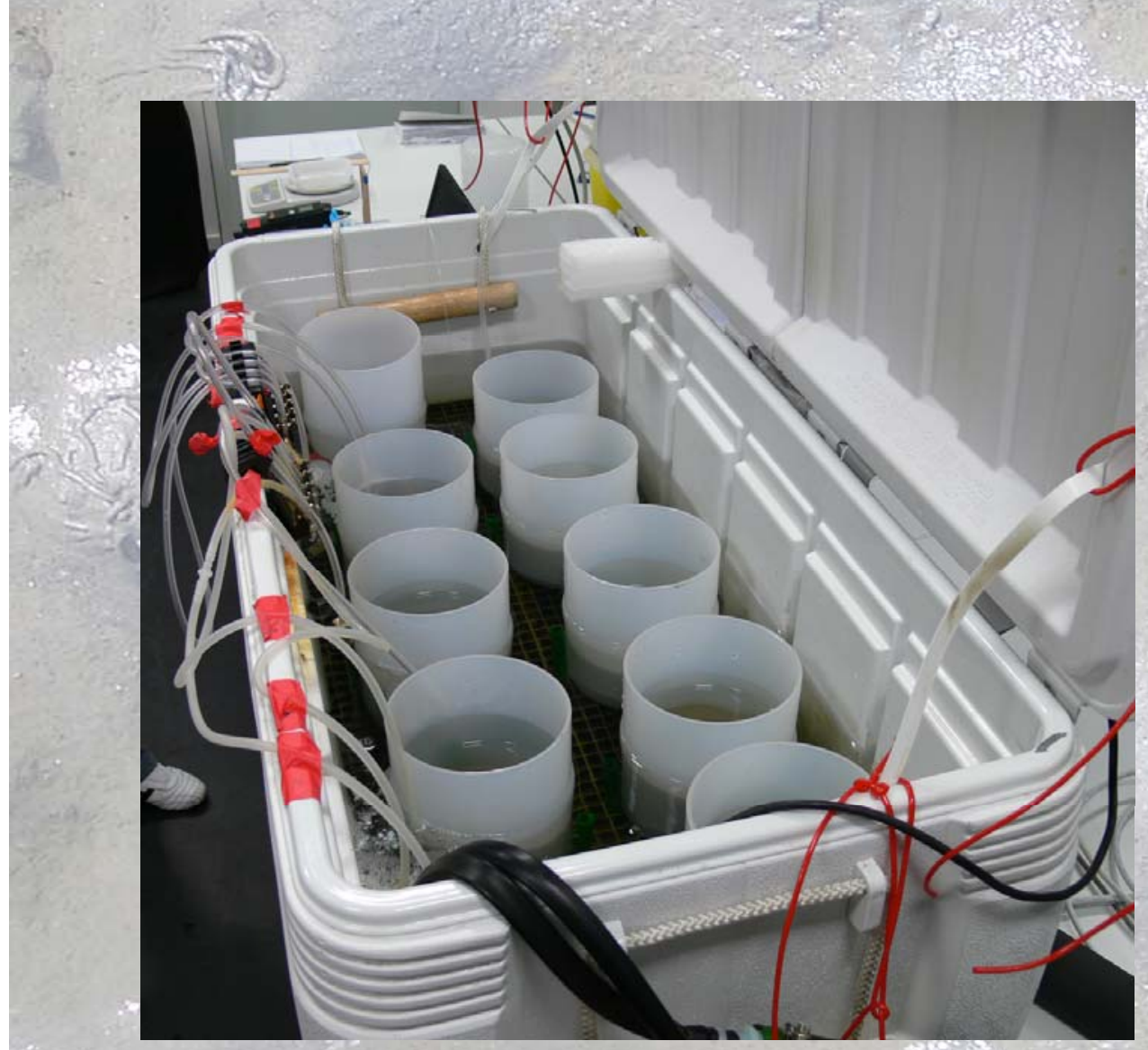

Experimental setup

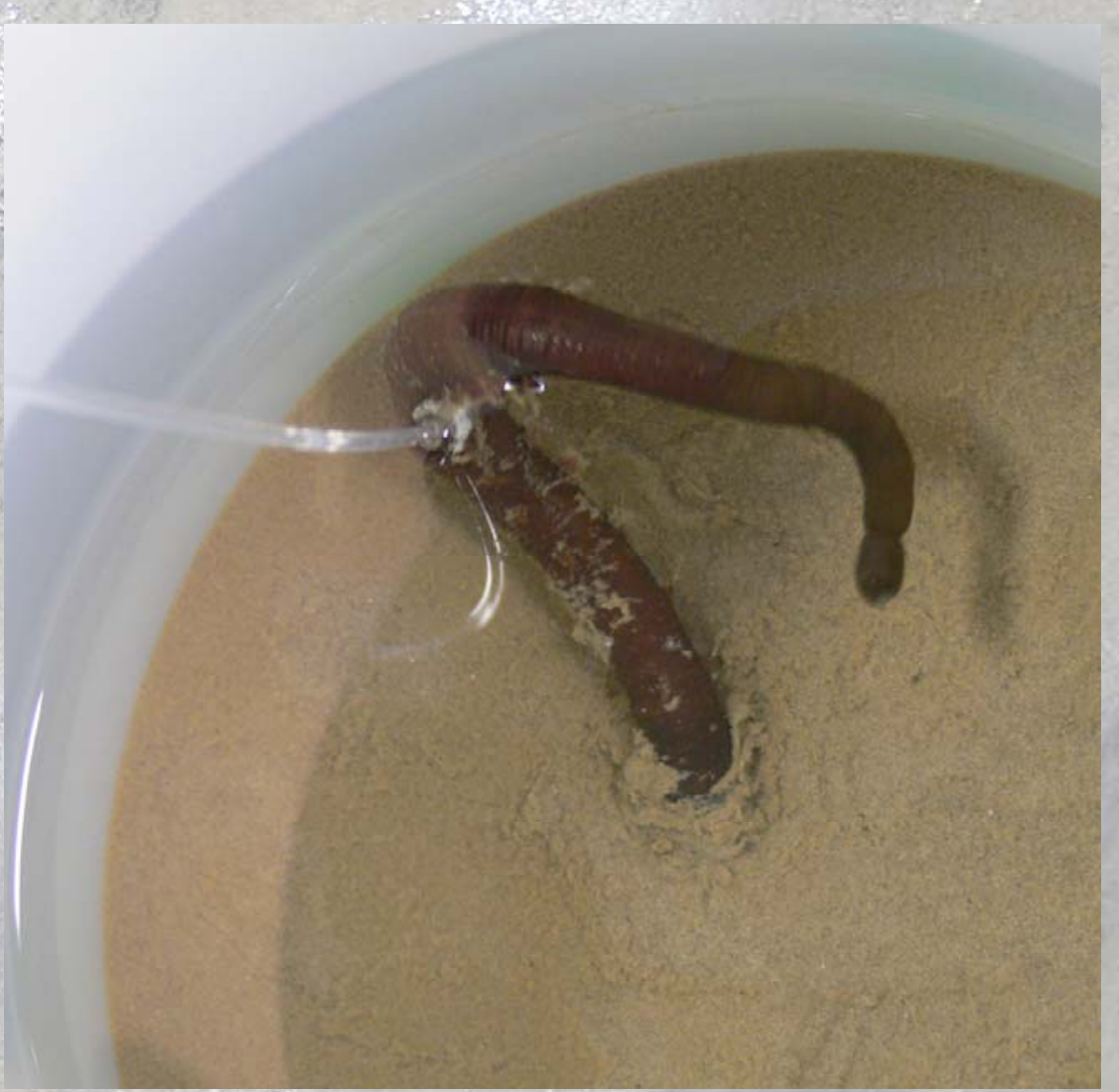

Worm digging into sediment 


\section{Latitudinal adaptation}

visible in summer animals from 3 populations:

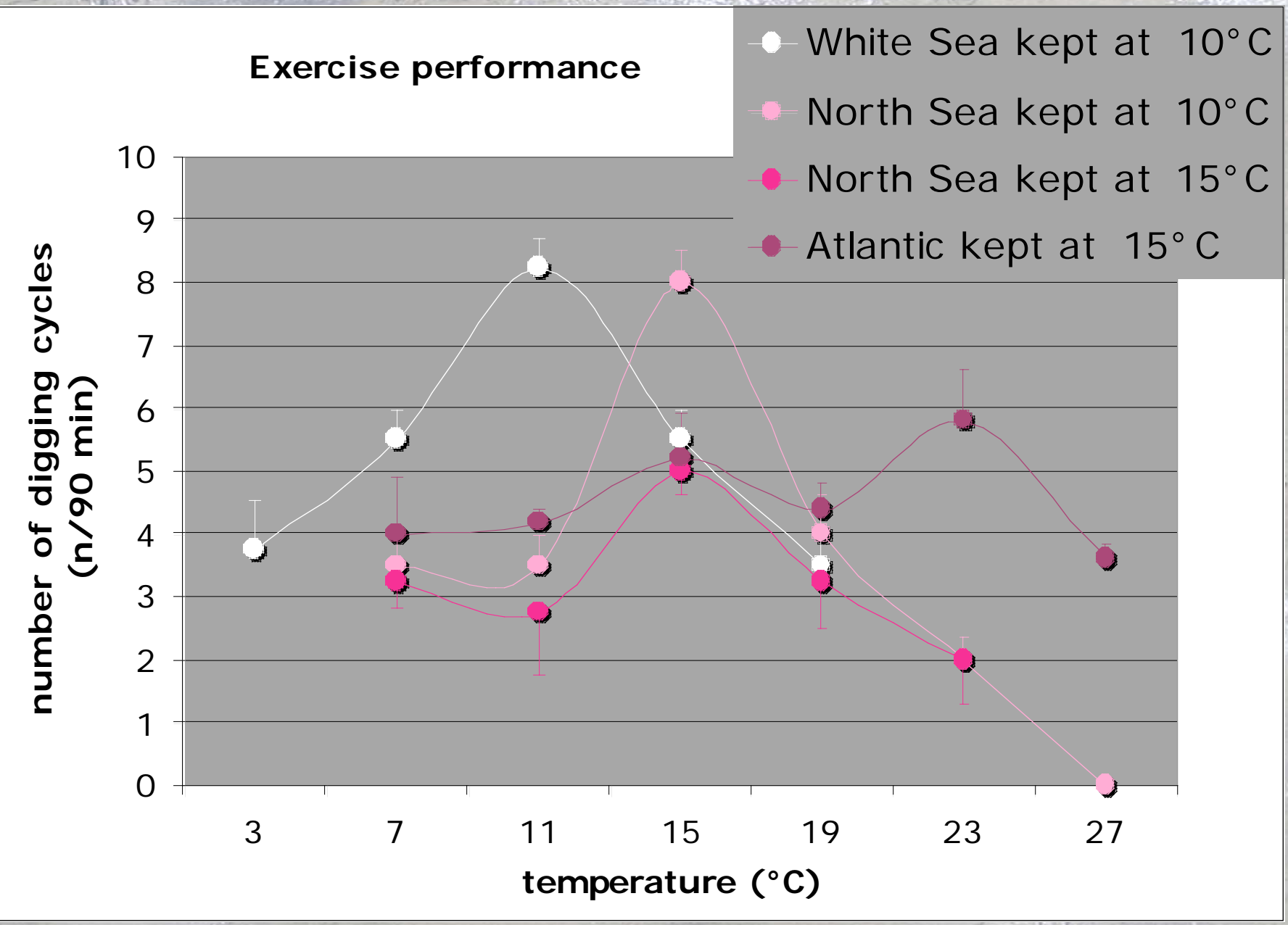

Performance optima:

White Sea

$11^{\circ} \mathrm{C}$

North Sea

$15^{\circ} \mathrm{C}$

Atlantic $23^{\circ} \mathrm{C}$ 


\section{Seasonal acclimatisation}

shown in summer and winter animals from the same population:

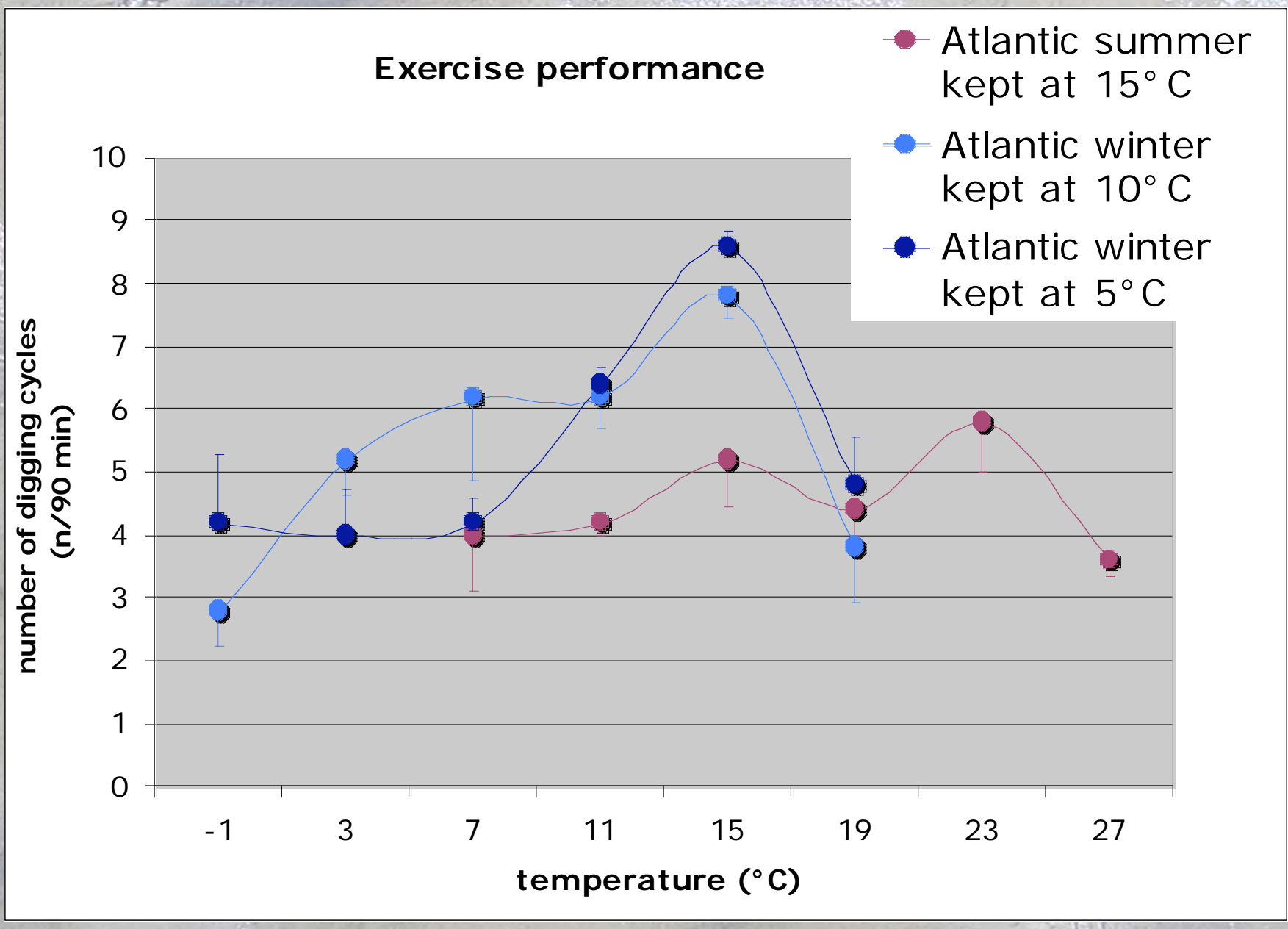

Performance optima:

Atlantic summer $23^{\circ} \mathrm{C}$

Atlantic winter $15^{\circ} \mathrm{C}$ 


\section{Seasonal acclimatisation}

shown in summer and winter animals from the same population:

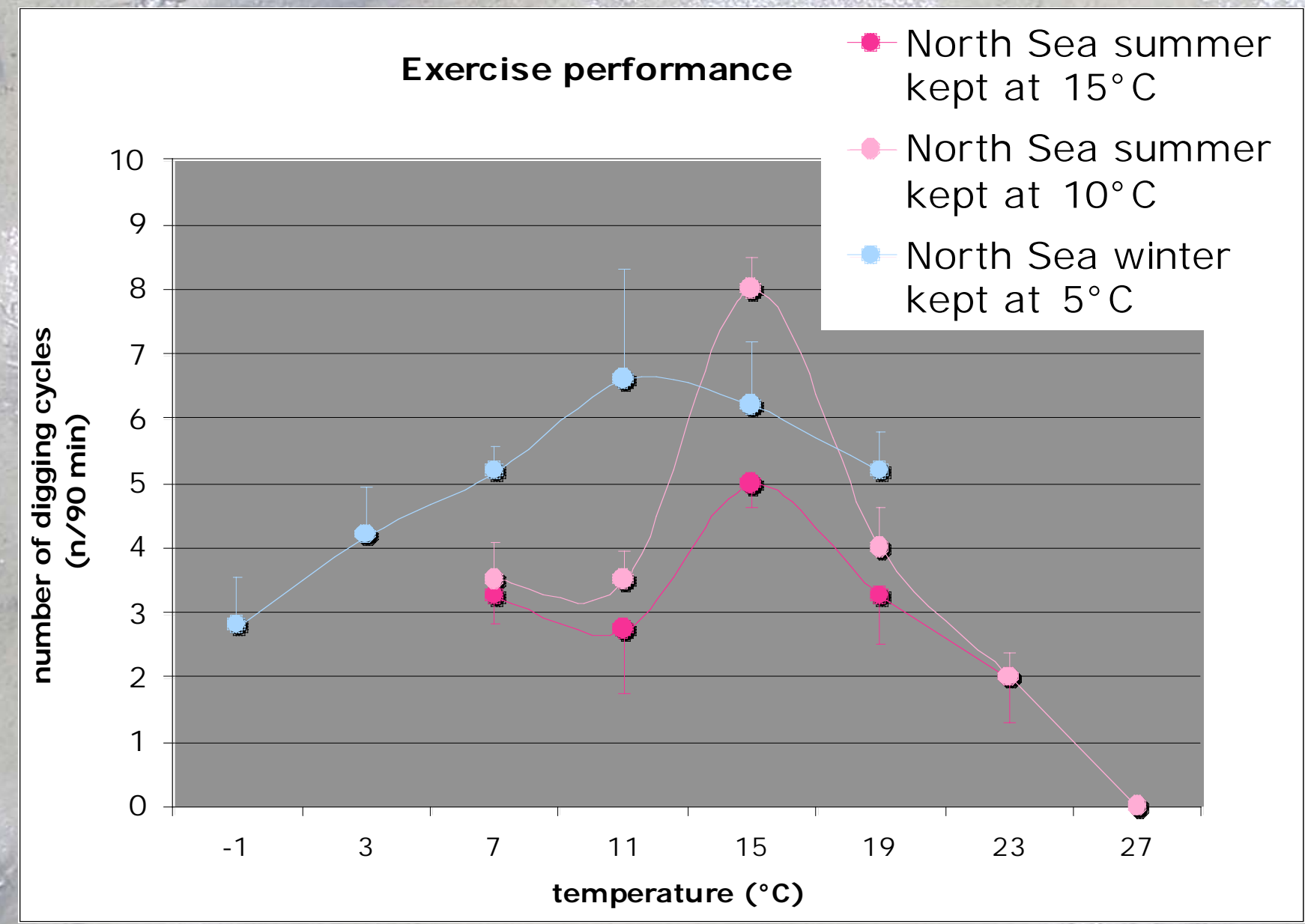

Performance optima:
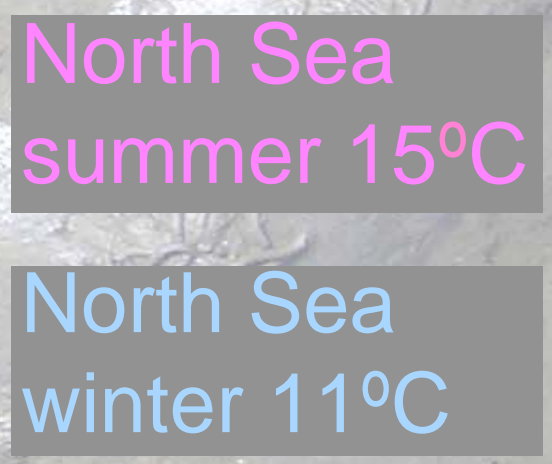


\section{Protein biosynthesis (= growth?)}

Method:
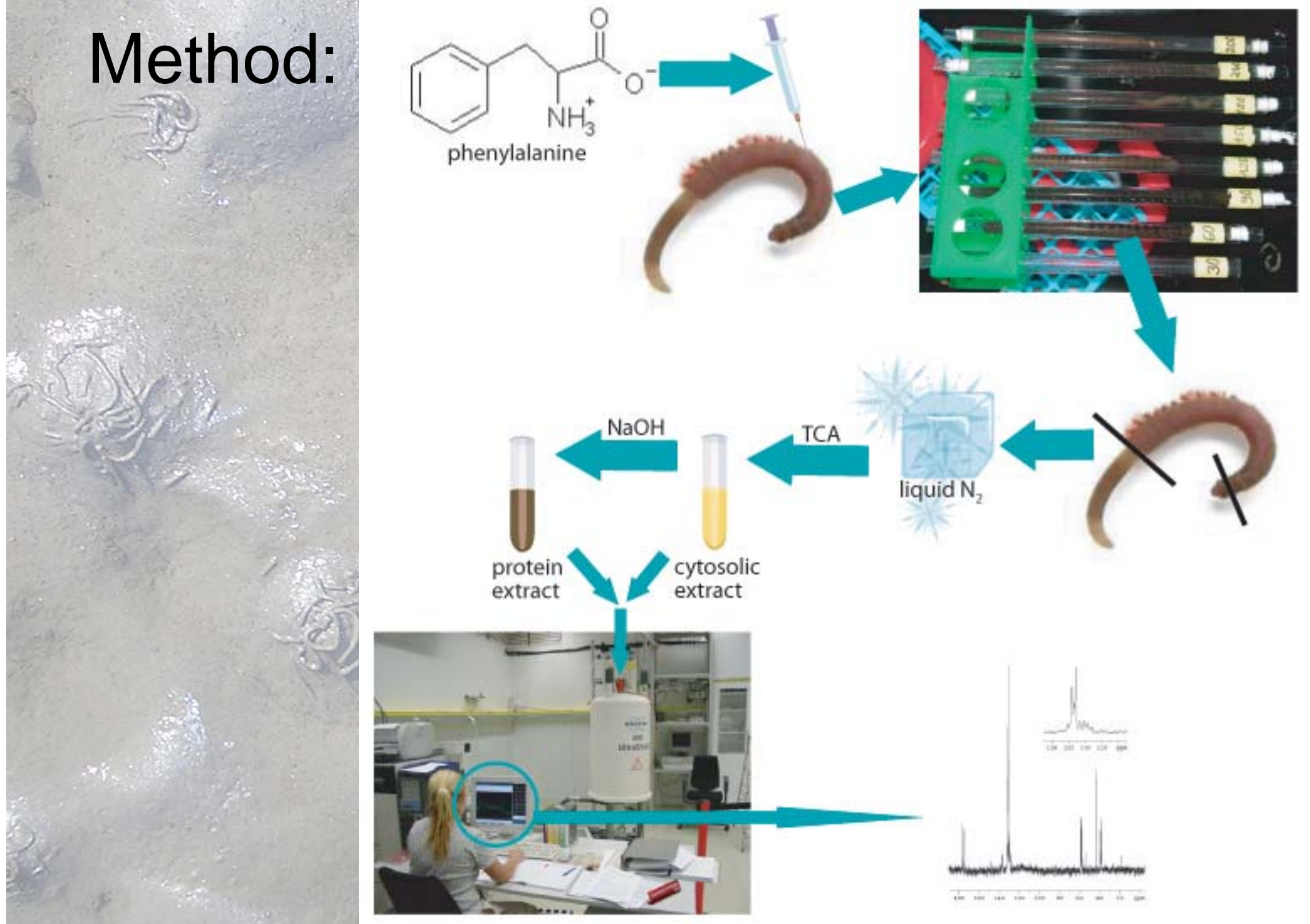

Forschungsgemeinschaft AQUA

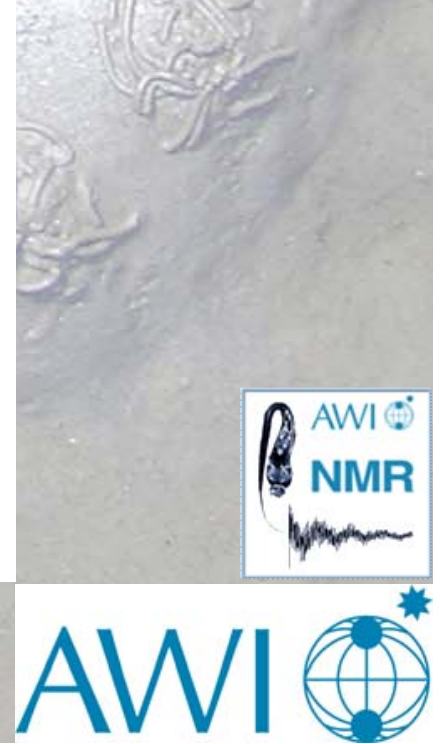




\section{Protein biosynthesis}

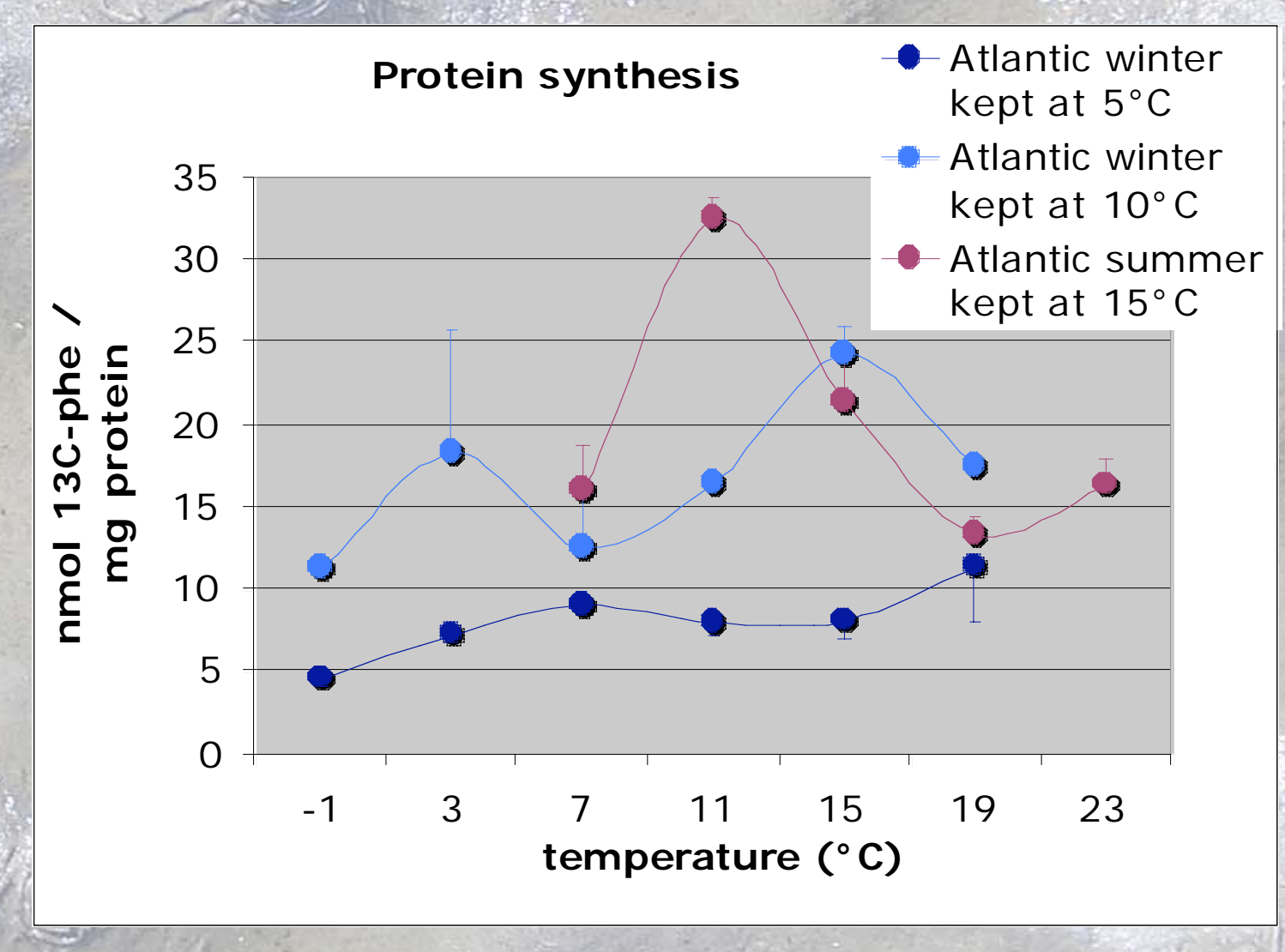

Atlantic:

- Highest synthesis performance in summer animals: performance optimum at $11^{\circ} \mathrm{C}$

- Protein synthesis detectable in winter animals kept at $10^{\circ} \mathrm{C}$ : performance optimum at $15^{\circ} \mathrm{C}$ 


\section{Protein biosynthesis}

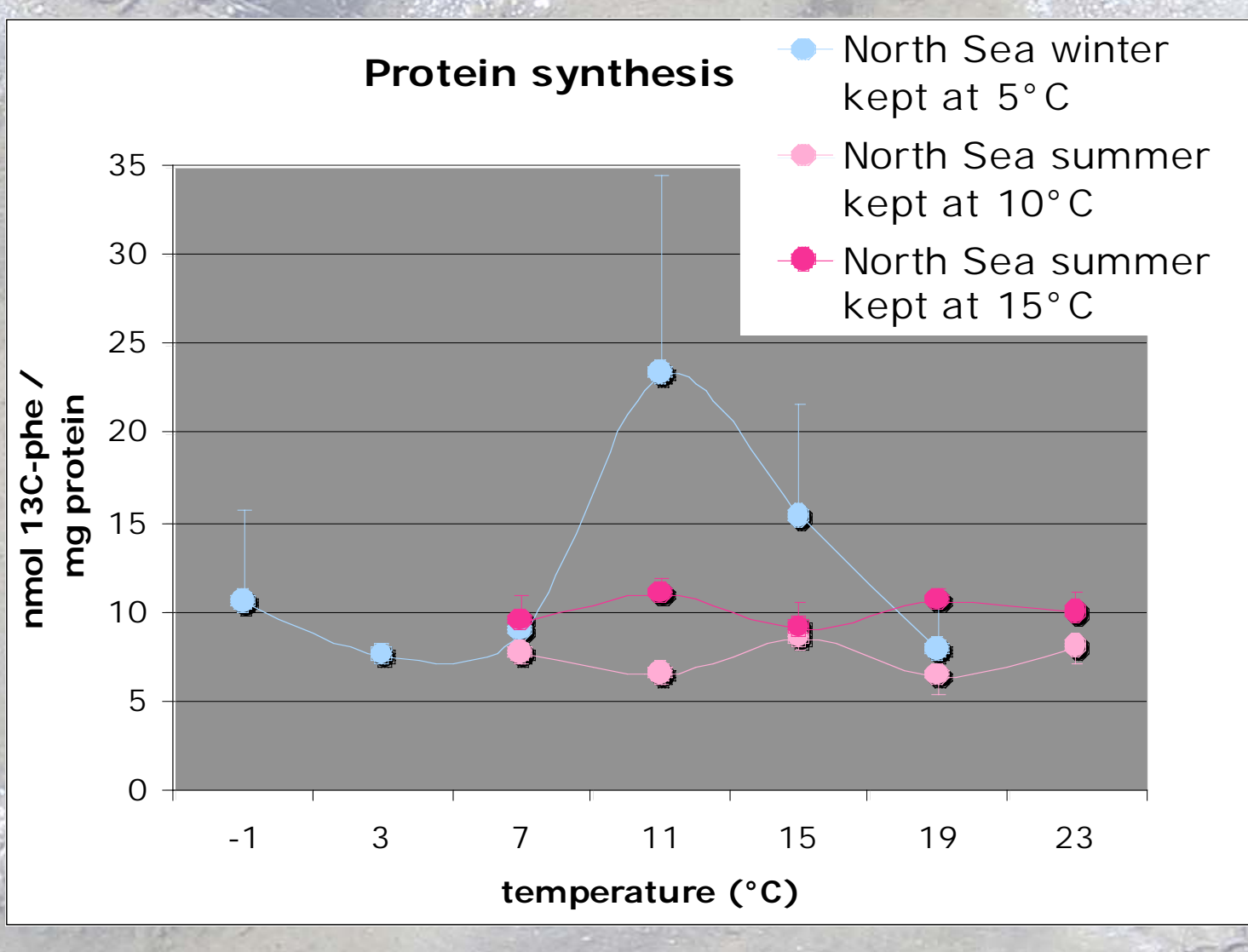

- Highest synthesis performance in winter animals: performance optimum at $11^{\circ} \mathrm{C}$

- No protein synthesis detectable in summer animals 


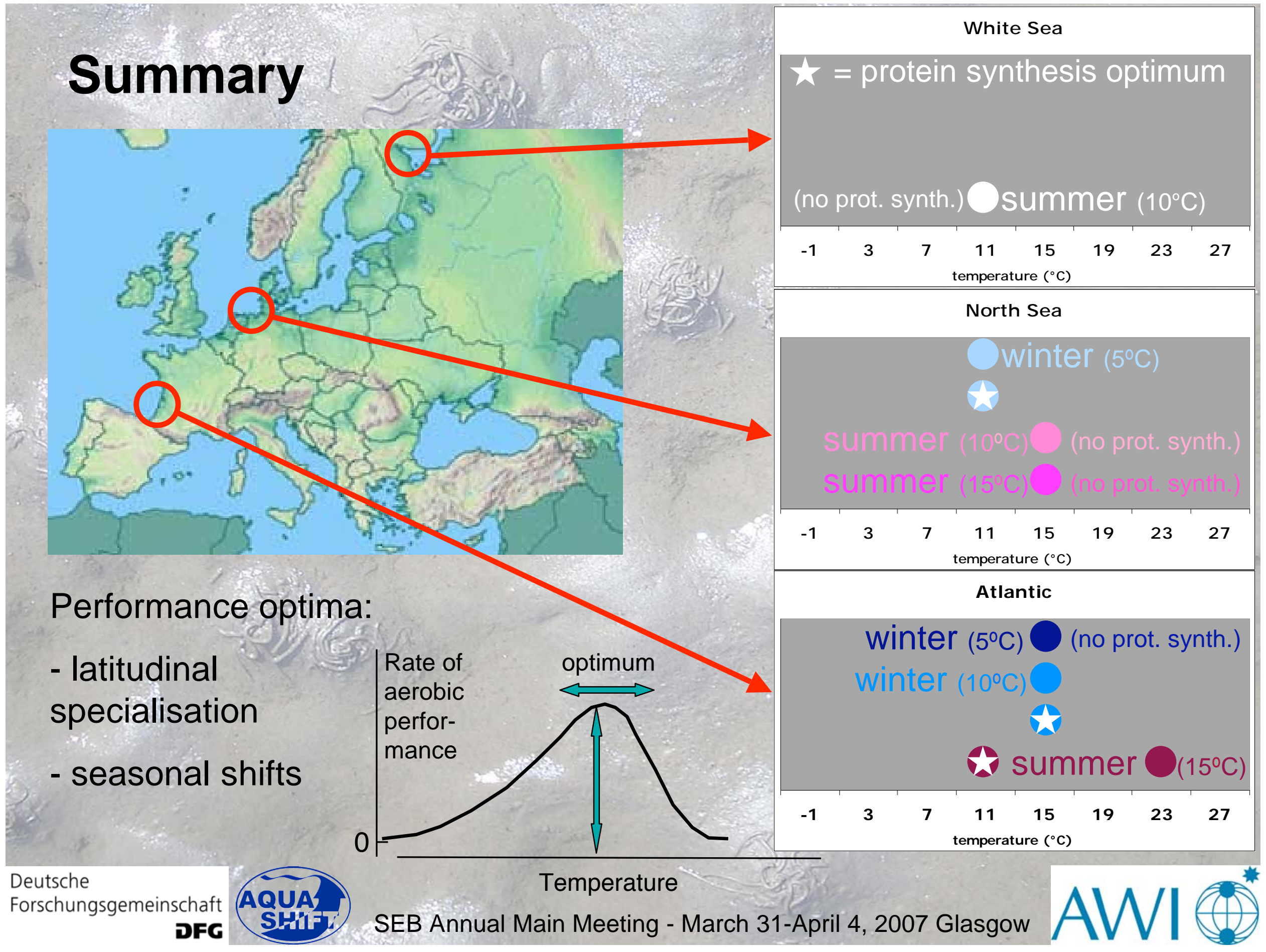




\section{Conclusions}

\section{Latitudinal adaptation}

(2) Performance optima found at higher temperatures with decreasing latitude

(2) White Sea and North Sea summer animals: groups kept at $10^{\circ} \mathrm{C}$ show a similar maximum exercise performance amplitude

(2) North Sea and Atlantic summer animals: groups kept at $15^{\circ} \mathrm{C}$ show a similar maximum exercise performance amplitude

(2) White Sea and North Sea summer animals: no protein synthesis detectable

(2) Atlantic summer animals: protein synthesis activity present, but performance optimum below habitat summer temperature range (2) North Sea and Atlantic winter animals: protein synthesis optima agree with exercise performance optima 


\section{Conclusions}

\section{Seasonal acclimatisation}

(0) Exercise performance optima shifted towards higher temperatures with summer acclimatisation

(2) Atlantic animals: shift by $8^{\circ} \mathrm{C}$; North Sea animals: shift by $4^{\circ} \mathrm{C}$ (2) Lower exercise performance amplitudes in summer than in winter

(2) protein synthesis performance optima located outside naturally experienced temperature range in winter and summer $=>$ maximum activity expected in spring 


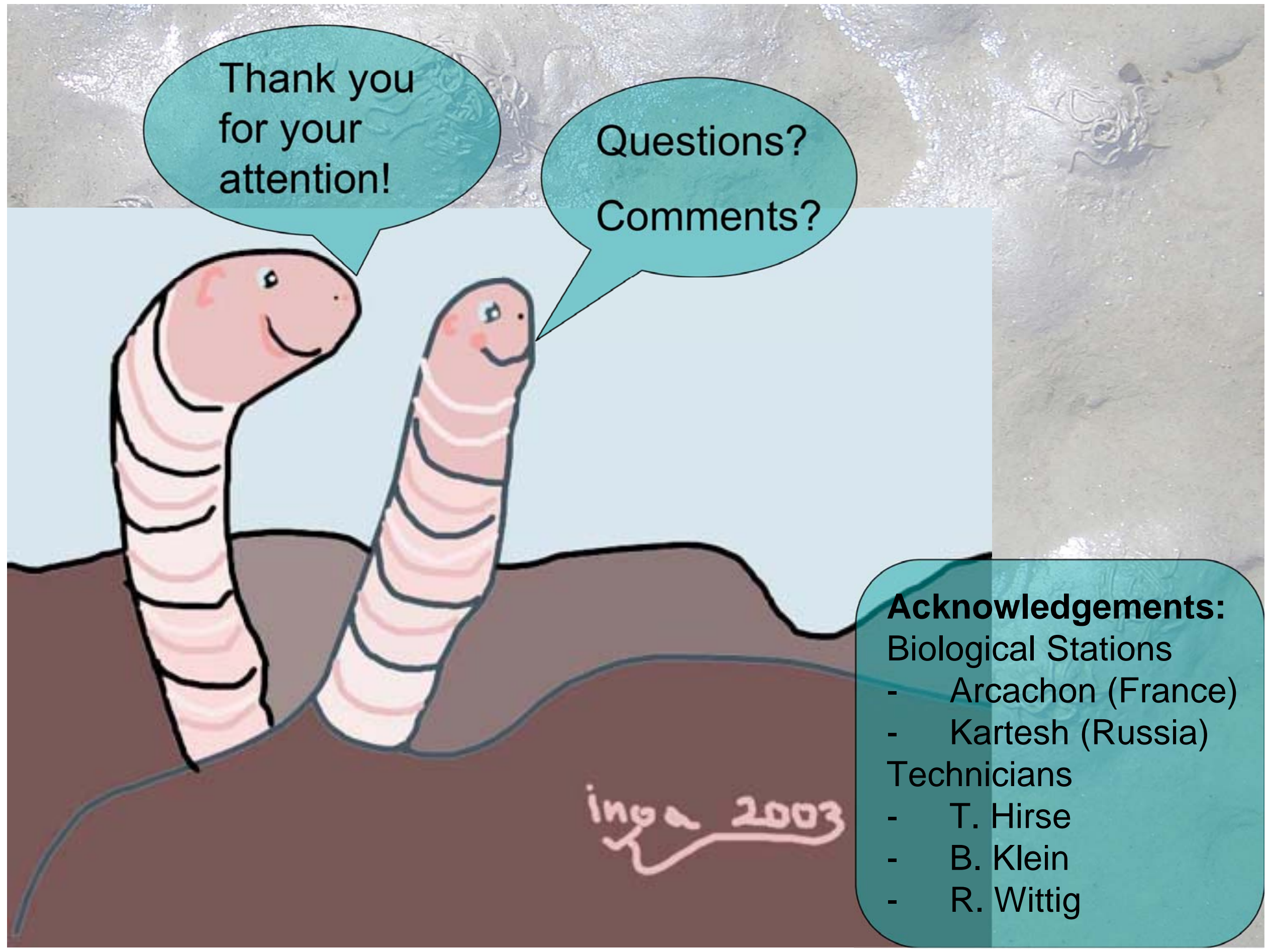

